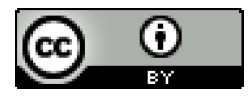

Esta obra está sob o direito

de Licença Creative

Commons Atribuição 4.0

Internacional.

\title{
SAÚDE MENTAL: AS PRINCIPAIS CAUSAS DO AFASTAMENTO DOS PROFISSIONAIS DA EDUCAÇÃO DOS SEUS TRABALHOS
}

Betijane Soares de Barros ${ }^{1}$

Andrea Marques Vanderlei Fregadolli ${ }^{2}$

Jamyle Nunes de Souza Ferro ${ }^{3}$

\section{RESUMO}

A saúde mental dos profissionais da educação é um tema que adquire crescente relevância científica, pois esta profissão é considerada como uma das mais estressantes. O presente trabalho tem por objetivo analisar as causas dos transtornos mentais relacionados aos profissionais da educação. Trata-se de uma pesquisa documental sistemática. Os documentos analisados estavam disponíveis no Portal Jusbrasil. Adotaram-se como critérios de inclusão, artigos de opinião de especialista, publicados no período de 2014 a 2020. Enquanto os critérios de exclusão foram documentos repetidos e que não contemplam a relação entre saúde mental e afastamento de profissionais da educação. Foi possível concluir que os profissionais da educação apresentam níveis elevados de sofrimento mental, muito superior ao esperado em outras categorias profissionais. As doenças preexistentes, o elevado número de alunos por turma, a carga horária de trabalho no ambiente escolar e a continuidade do trabalho em casa constituíram situações que corroboram com o sofrimento mental.

Palavras-chave: Saúde Mental. Profissional. Afastamento; Educação.

Submetido em março de 2020 e aceito em maio de 2020.

\footnotetext{
${ }^{1}$ Doutora em Ciências da Educação (Faculdade de Ciências, Letras e Educação do Paraná). Doutora em Ciências da Saúde (Absoulute Christian University). Mestre em Ciências da Saúde (UFAL). Diretora do IMAS. ${ }^{2}$ Doutora em Ciências (UFAL). Mestre em Modelagem Computacional do Conhecimento (UFAL). Professora da graduação de Medicina e do Mestrado Ensino na Saúde da Faculdade de Medicina (UFAL).

3 Bacharel em Farmácia pela Universidade Federal de Alagoas (UFAL, 2009). Mestre em Ciências da Saúde pela Universidade Federal de Alagoas (UFAL, 2012). Doutora em Ciências da Saúde pela Universidade Federal de Alagoas (UFAL, 2016). Pós-doutorado pela Universidade Federal de Pernambuco (UFPE, 2018)
} 


\section{INTRODUÇÃO}

As transformações que têm acontecido em relação à função do professor, como a fragmentação do seu trabalho e a complicação das demandas que lhe são conferidas, acontecem com um processo histórico de rápida mudança do contexto social (BIROLIM et al., 2019).

Com isso, aumenta-se as responsabilidades e cobranças sobre esse profissional, de modo que ele precisa apresentar, além das competências pedagógicas, habilidades sociais e emocionais (FAVATTO, BOTH, 2019).

Em função disso, a saúde mental do professor é um tema de pesquisa que adquire crescente relevância e vem sendo motivo de grande preocupação por parte de profissionais, gestores institucionais e entidades sindicais e governamentais (ARAÚJO, PALMA, ARAÚJO, 2017). A docente é considerada pela Organização Internacional do Trabalho (OIT) uma das profissões mais estressantes que existe, mas nos últimos anos, ensinar se tornou uma atividade desgastante, com repercussões visíveis na saúde mental, física e na atuação profissional. Danos

\section{METODOLOGIA}

Trata-se de uma pesquisa documental sistemática, a qual segue as osteomusculares e transtornos mentais, como apatia, estresse, desesperança e desânimo, são formas de adoecimento que têm sido identificadas em professores (DIEHL; MARIN, 2016).

Desse modo, independentemente do nível de ensino e instituição (pública ou privada), pode-se ver que repercussões negativas na saúde do professor podem ser causadas pelo intenso envolvimento emocional com os problemas dos alunos, a desvalorização social do trabalho, a falta de motivação para o trabalho, a exigência de qualificação do desempenho, as relações interpessoais insatisfatórias, as classes numerosas, a inexistência de tempo para descanso e lazer e a extensiva sobre carga de trabalho (SILVA, 2015).

$\mathrm{O}$ presente trabalho analisou produções científicas publicadas entre 2015 e 2020, no site Jusbrasil, com vista a identificar principais causas dos problemas mentais relacionados aos profissionais da educação. Espera-se que novos estudos possam contribuir para promoção da saúde mental desses profissionais.

mesmas etapas (Figura 1) da revisão sistemática integrativa, a saber: definição do tema; seleção da pergunta norteadora e escolha da estratégia de busca; descritores 
e bases de dados mais eficazes no levantamento das publicações; escolha dos critérios de inclusão e exclusão; identificação dos estudos préselecionados e selecionados por meio da leitura dos agentes indexadores das publicações, como resumos, palavraschave e títulos, bem como a organização dos estudos pré-selecionados e a identificação dos estudos selecionados; categorização dos estudos selecionados, com a elaboração e o uso da matriz de síntese, além da análise das informações; a formação de uma biblioteca individual e a avaliação crítica dos estudos

\section{RESULTADOS}

Foram detectadas 1.907 publicações científicas nos bancos de dados, das quais selecionados; análise, interpretação e discussão dos resultados e a apresentação da revisão em formato de artigo, o qual contempla as propostas para estudos futuros.

Os documentos analisados estavam disponíveis no Portal Jusbrasil. Adotaram-se como critérios de inclusão, artigos de opinião de especialista, publicados no período de 2014 a 2020 . Enquanto os critérios de exclusão foram documentos repetidos e que não contemplam a relação entre saúde mental e afastamento de profissionais da educação.

57 eram artigos disponíveis após o uso dos filtros, desses foram feitos 17 downloads, que obedeceram aos critérios de inclusão, sendo submetidos às etapas da revisão integrativa.

Figura 1 - Corresponde ao total de documentos disponíveis na Plataforma JUSBRASIL obtidos por string de busca.

\begin{tabular}{|l|l|c|c|c|}
\hline \multicolumn{1}{|c|}{ String de busca } & 3ases de dados & $\begin{array}{c}\text { Total de } \\
\text { ublicações sem } \\
\text { o filtro }\end{array}$ & $\begin{array}{c}\text { Publicações } \\
\text { disponíveis após } \\
\text { aplicar os filtros }\end{array}$ & $\begin{array}{c}\text { Publicações } \\
\text { aproveitadas na } \\
\text { Revisão } \\
\text { Sistemática } \\
\text { Integrativa }\end{array}$ \\
\hline $\begin{array}{l}\text { saúde mental" AND } \\
\text { rofissional educação } \\
\text { ND afastamento }\end{array}$ & $\begin{array}{c}\text { Plataforma } \\
\text { JUSBRASIL }\end{array}$ & 1.907 & 57 & 17 \\
\hline
\end{tabular}

Fonte: autoria própria. 


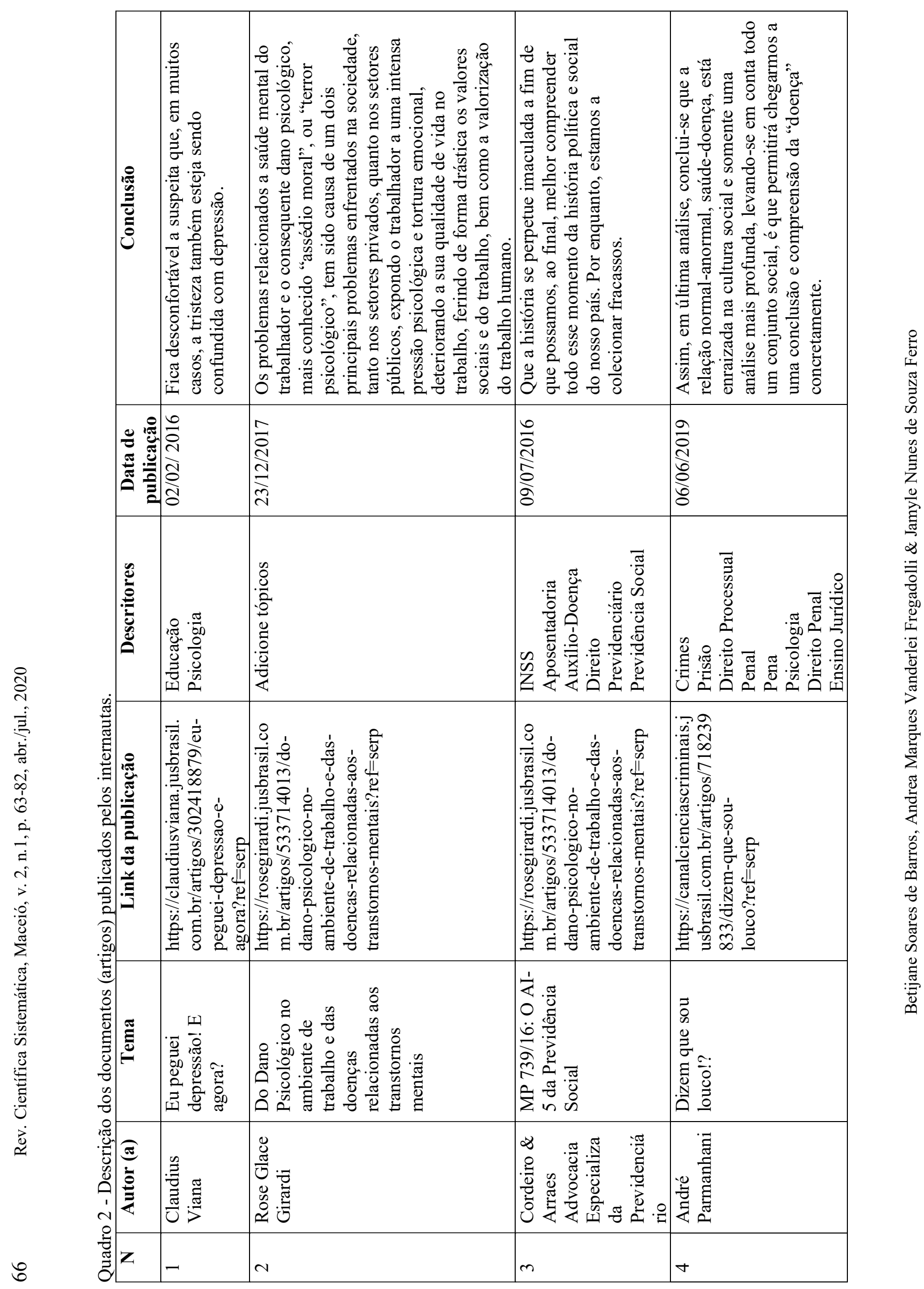




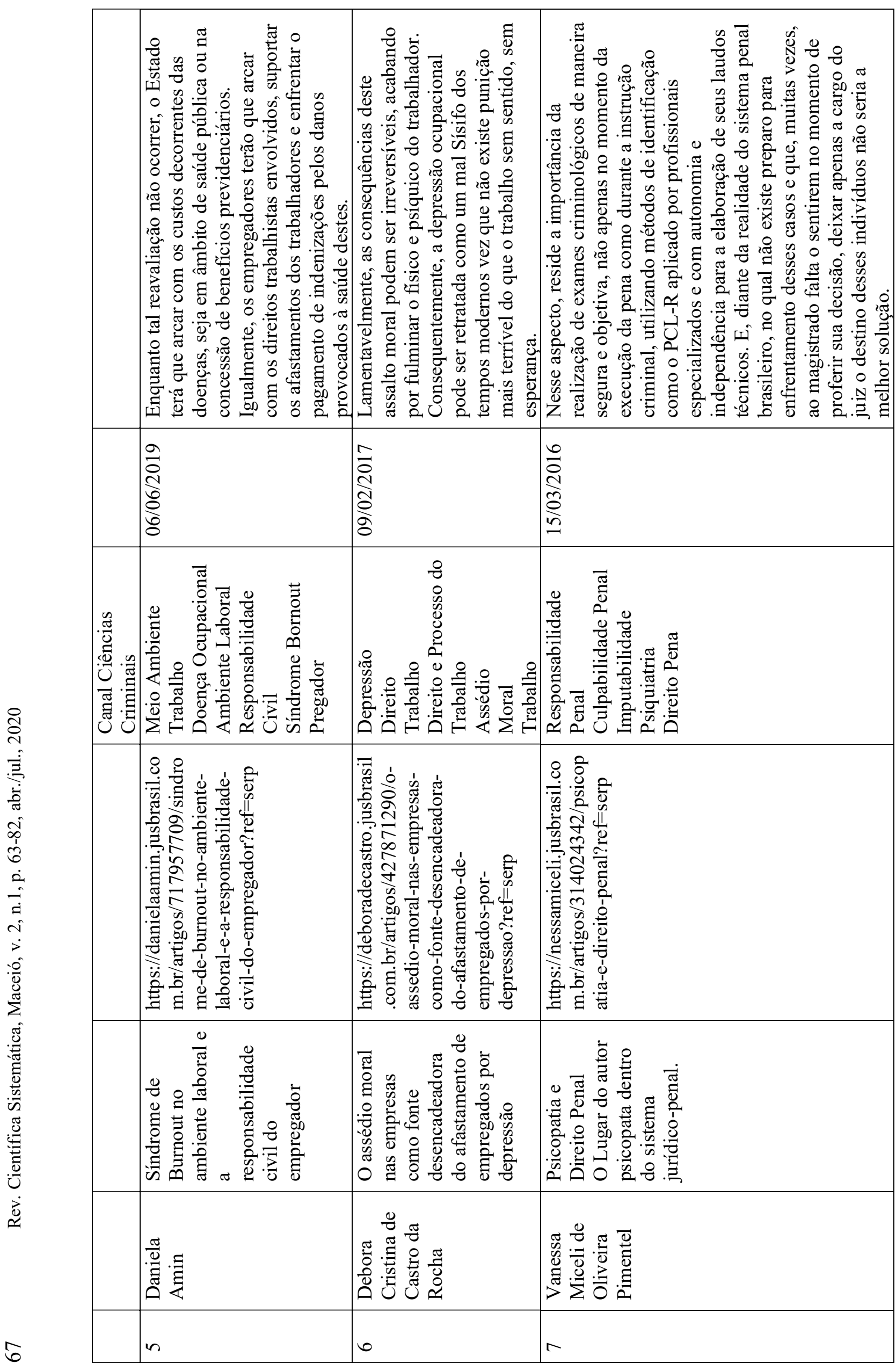

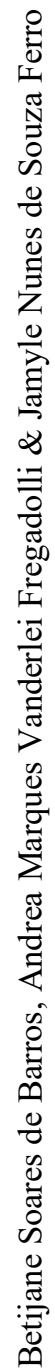




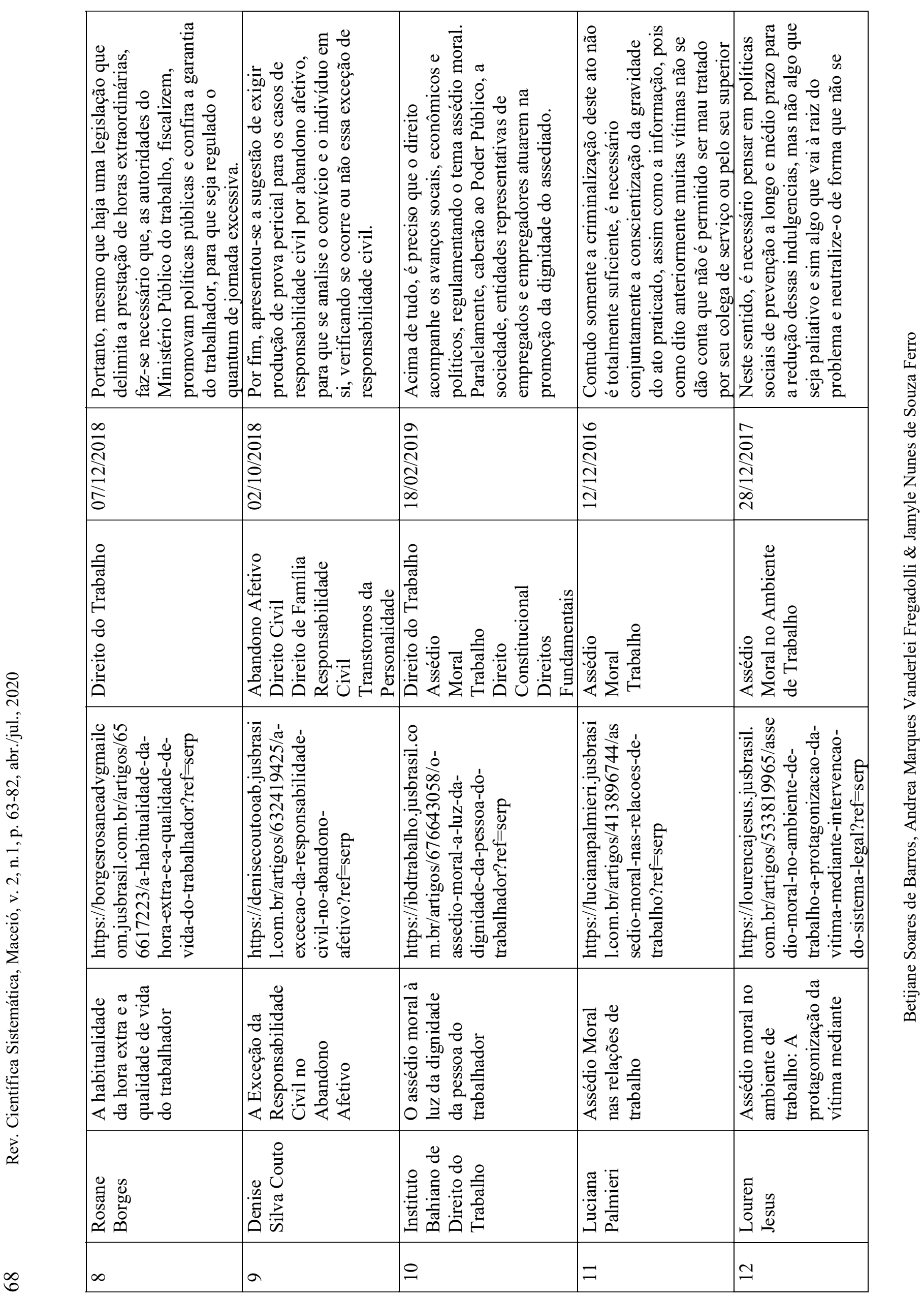




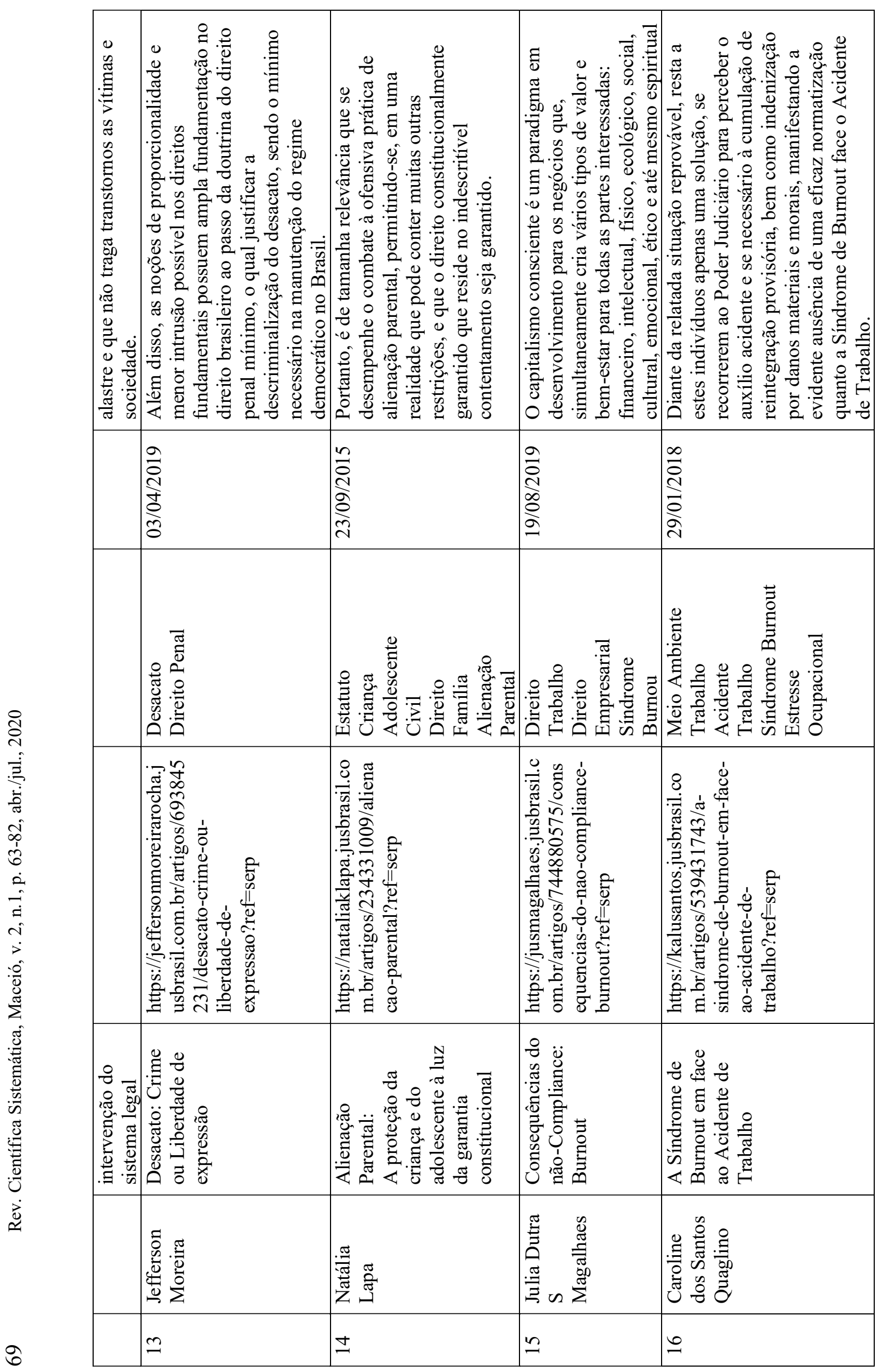

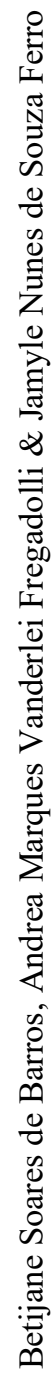




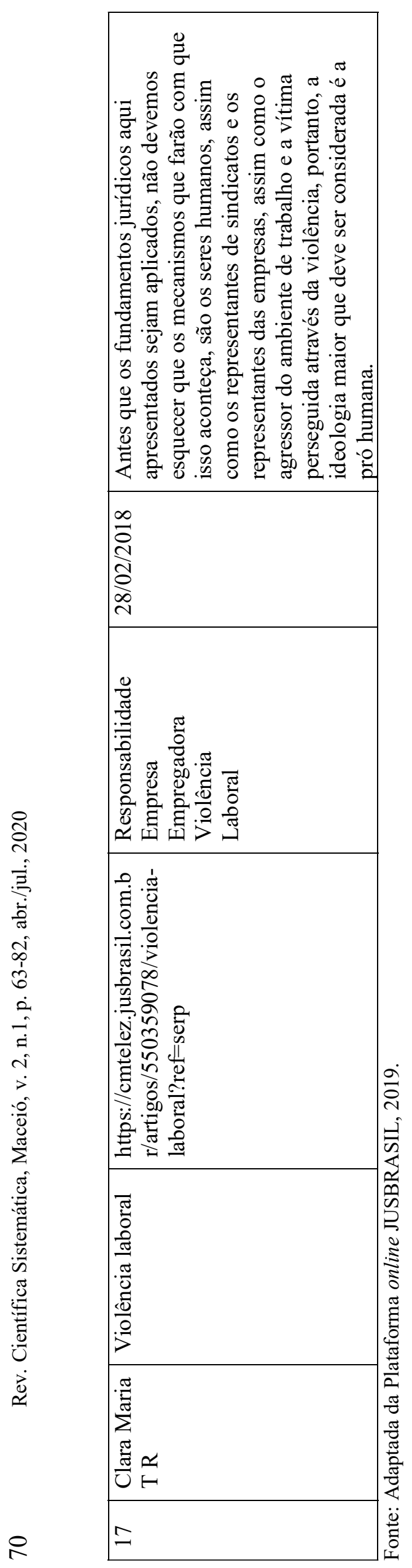


O corpo textual foi analisado por meio da frequência de palavras, que originou a nuvem de palavras (Figura 2) criada na Plataforma online WordArt. Esta

Figura 2. Nuvem de palavras.
ferramenta
agrupa
e organiza graficamente as palavras-chave evidenciando-as as mais frequentes.

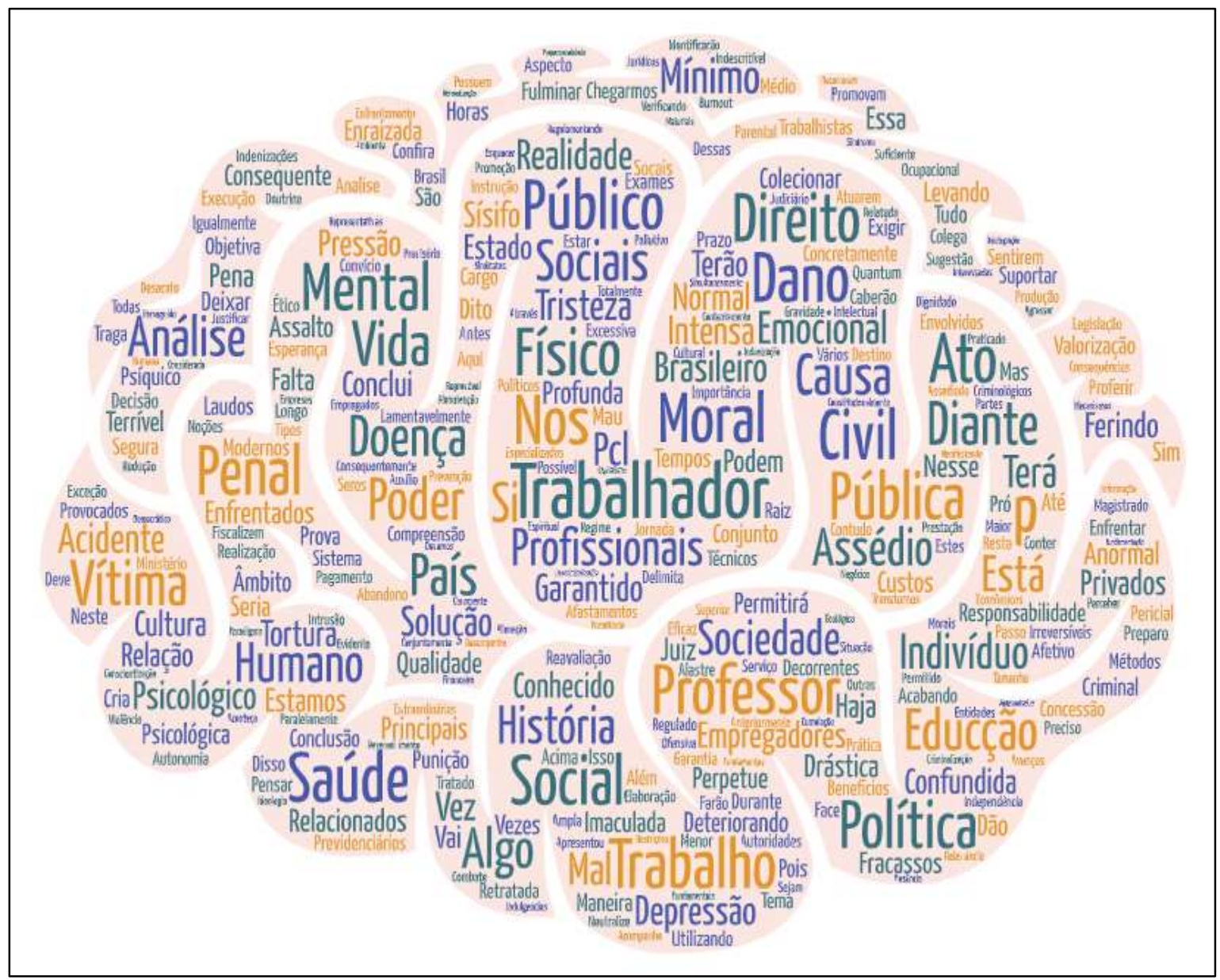

Fonte: autoria própria.

Por meio da Figura 2, foi possível observar que as palavras em evidência na nuvem pertencem as categorias desenvolvidas a partir da análise de conteúdo de Bardin. Todas as categorias derivam da sua frequência (Tabela 1), que diz respeito ao seu quadro referencial. Em consonância ao objetivo deste trabalho, optou-se por descrever as palavras que apresentaram frequência total no texto e, a partir de seus sentidos nos campos textuais, tinham maior relevância para as representações sociais sobre a saúde mental e afastamento dos profissionais da educação, como apresentado na Figura1. 
Tabela 1 - Frequência das palavras presentes nos textos publicados pelos internautas na Plataforma JUSBRASIL.

\begin{tabular}{|c|c|c|c|}
\hline PALAVRAS & FREQUÊNCIA & INTERNAUTAS/ARTIGO & CATEGORIAS \\
\hline \multirow{3}{*}{$\begin{array}{l}\text { Saúde mental } \\
\text { Profissional/Profissionais/ } \\
\text { empregado/trabalhador } \\
\text { /Professor } \\
\text { Educação }\end{array}$} & 160 & $1,2,3$ & \multirow{3}{*}{$\begin{array}{l}\text { Saúde mental e } \\
\text { profissionais da } \\
\text { educação }\end{array}$} \\
\hline & 908 & $1,2,3,5,6,7,8,9,10,11,12,13,15,16$ & \\
\hline & 50 & $\begin{array}{c}1,2,3,5,6,7,9,10,11,12,13 \\
14,15,16\end{array}$ & \\
\hline \multirow{3}{*}{$\begin{array}{l}\text { Afastamentos } \\
\text { Profissional/Profissionais/ } \\
\text { empregado/trabalhador } \\
\text { /Professor } \\
\text { Educação }\end{array}$} & 41 & $2,5,6,8,15,16,17$ & \multirow{3}{*}{$\begin{array}{l}\text { Afastamentos } \\
\text { dos profissionais } \\
\text { da educação }\end{array}$} \\
\hline & 908 & $1,2,3,5,6,7,8,9,10,11,12,13,15,16$ & \\
\hline & 50 & $1,2,3,4,5,6,7,9,10,11,12,13,14,15,16$ & \\
\hline \multirow{3}{*}{$\begin{array}{l}\text { Saúde } \\
\text { Trabalho }\end{array}$} & 219 & $\begin{array}{c}1,2,3,4,5,6,7,8,9,10,11,12 \\
13,14,15,16,17 \\
\end{array}$ & \multirow[t]{3}{*}{$\begin{array}{l}\text { Dano a saúde e } \\
\text { trabalho }\end{array}$} \\
\hline & 108 & $1,2,3$ & \\
\hline & 1.255 & $\begin{array}{c}1,2,3,4,5,6,7,8,9,10,11,12 \\
13,14,15,16,17 \\
\end{array}$ & \\
\hline \multirow{3}{*}{$\begin{array}{l}\text { Políticas públicas } \\
\text { Saúde } \\
\text { Trabalho }\end{array}$} & 112 & $5,8,17$ & \multirow{3}{*}{$\begin{array}{l}\text { Políticas } \\
\text { públicas voltada } \\
\text { para saúde e } \\
\text { trabalho }\end{array}$} \\
\hline & 108 & $1,2,3$ & \\
\hline & 1.255 & $\begin{array}{c}1,2,3,4,5,6,7,8,9,10,11,12 \\
13,14,15,16,17 \\
\end{array}$ & \\
\hline
\end{tabular}

Fonte: autoria própria.

\section{DISCUSSÃO}

Os profissionais da educação precisam de ações positivas, para fins de facilitar as condições de trabalho para que possam enfrentar as dificuldades que acarreta no seu dia-a-dia. Muitas dessas dificuldades vivenciadas no seu trabalho, resultando no adoecimento e no afastamento do seu trabalho (CORTEZ et al., 2017). Podemos observar que essa mudança está de certa forma distante de ocorrer, assim cada vez mais tendo

profissionais afastados de suas funções (MARANGONI et al.,2016).
Seguem abaixo, as categorias temáticas elaboradas a partir da revisão sistemática integrativa.

\section{Saúde mental e profissionais da educação}

No processo de transformação e adaptação que o sistema exige realiza historicamente que os profissionais da educação façam algumas mudanças, para que não ocasionem problemas mentais. Para a sobrevivência e a expansão de suas atividades profissionais dentro de um sistema capitalista, estas mudanças atuam tanto nas formas de exploração do trabalho docente, como em suas funções mentais, incluindo aí a criação e utilização 
de novas metodologias para melhor adaptações profissionais, quanto nas características de reprodução ideológica e material da força de trabalho (MEDEIROS et al., 2016).

"Reduções das realizações pessoais e profissionais ficam extremamente comprometidas. Entende-se que surge outro tipo de pessoa, diferente da anterior, mais fria e descuidada, acarretando a queda da autoestima, que às vezes leva à depressão." (INTERNALTA 16).

Simplesmente se joga no natural fragmentação e se transfere para organismos da chamada sociedade a culpa de tantos problemas causados com profissionais da educação relacionados a saúde mental, entrando aí um soberano desprezo pela nossa querida docência (SOARES et al., 2014).

"Mas todo sofrimento é doença? Todo mal-estar deve ser posto sob tutela médica? A depressão é confundida com tristeza, é o argumento-chefe dos profissionais e instituições que pregam a expansão dos critérios diagnósticos de depressão. Mas qual o espaço nesses critérios para compreender, discutir e enfrentar a solidão, a melancolia, o desânimo ou o tédio nascido das condições que os produzem na vida diária e nas relações do indivíduo com a sociedade? Fica a desconfortável suspeita que, em muitos casos, a tristeza também esteja sendo confundida com depressão.” (INTERNALTA 6).

Dessa forma, o mercado começa a demarcar as fronteiras da educação, lhes exigindo que facilitem seu livre movimento, intervindo somente nas áreas não mercantilizáveis. Tem-se, assim, por um lado, a redução e focalização da ação estatal para aqueles casos mais imediatos e urgentes sejam resolvidos e, por outro lado, a consequente transformação em mercadoria dos serviços educacionais a serem adquiridos no mercado pelo cidadão consumido. No que se refere aos docentes, pouca atenção tem sido dada aqueles envolvidos com a educação (DIEHL; MARIN, 2016).

Quando se trata das consequências das transformações ocorridas hodiernamente no fazer profissional dos professores, a esmagadora maioria das pesquisas e textos ignora o que ocorre entre os docentes e sua profissão. Este segmento desconhece o que vem acontecendo no interior de sua própria categoria profissional, haja vista não só a ausência de estudos, mas também de dados sobre a saúde mental dos docentes (CORTEZ et al., 2017).

A conjugação dos elementos necessários a essa reconfiguração implica em uma nova sociabilidade, que se inicia com o redimensionamento dos professores no que diz respeito a saúde mental. Novamente, a subjetividade dos docentes precisa ser capturada e reconfigurada a partir de um padrão no qual a luta deve ser uma escolha em comum a todos (BIROLIM et al.,2019). 
Para tanto, um dos caminhos mais eficazes é a reconfiguração do mundo sobre o trabalho docente por meio de reformas no sistema de educação. Entretanto, estas reformas não afetam somente os ditos currículos ou pedagogias do ensino, afetam também aqueles que trabalham na área da educação, causandolhes transtornos físicos e mentais (BIROLIM et al.,2019).

A psicologia vem se debruçando na tentativa de compreender a relação entre trabalho e saúde mental. Os pesquisadores da área seguem diferentes abordagens; as três mais frequentes são: a teoria do estresse, a psicodinâmica do trabalho e a abordagem epidemiológica (COSTA M, BARBOSA; CARRARO, 2014).

A teoria do estresse afirma que o estresse é uma síndrome específica constituída por alterações fisiológicas não específicas, resultantes da necessidade de adaptação e ajustamento frente às pressões do meio. Faz parte da vida dos seres humanos, porém se constitui prejudicial à medida que se torna crônico, podendo levar ao adoecimento. Por sua vez, a psicodinâmica do trabalho, privilegia a normalidade sobre a patologia. Essa teoria busca compreender o motivo pelo qual certos trabalhadores se mantêm psicologicamente equilibrados mesmo em condições desestruturastes. A abordagem epidemiológica e/ou diagnóstica parte do conceito de saúde preconizado pela Organização Mundial de Saúde - OMS que a considera como um constructo multidimensional que inclui o bem-estar físico, psíquico, social e espiritual (DIEHL; CARLOTTO, 2014).

“A "Síndrome de Burnout” está
associada a profissionais da área da
educação, saúde, assistência social,
recursos humanos, jornalista,
executivos, gerentes, entre outros
cargos que exigem um envolvimento
interpessoal intenso."
(INTERNALTA 2).

Contudo, os afastamentos, raras vezes oficializados, decorrentes de estresse, que constantemente encobrem o alcoolismo, a dependência química, a síndrome do pânico e a síndrome de Burnout, dentre outros transtornos, lombalgias, gastrites e depressão; ou mesmo a utilização de ansiolíticos, antidepressivos ou medicamentos conhecidos como tarja preta, estão experimentando um ascensor acelerado entre os professores.

\section{Afastamentos dos profissionais da educação}

$\mathrm{O}$ afastamento dos profissionais da educação dos seus respectivos trabalhos, pouco vem sendo visto e estudado. Quando na verdade temos visto que se faz necessário um ampla estudo sobre tal, pois, o trabalho para esses profissionais, ocupa um lugar fundamental na dinâmica 
subjetiva de suas vidas, podendo o trabalho ser fonte de garantia de subsistência, posição social, prazer e satisfação, para esses profissionais (MARANGONI et al. 2016). Contudo, quando o trabalho é desprovido de significados, sem suporte social, não valorizado ou quando representa fonte de ameaça à integridade pode desencadear sofrimento psíquico, bem como a necessidade do afastamento do trabalho (FAVATTO; BOTH, 2018).

"Tais características, se aplicadas
indistintamente pelas empresas
geram tensão emocional e estresse
crônico, criando condições que
predispõem os trabalhadores ao
adoecimento, resultando em
licenças médicas e afastamentos por
períodos longos." (INTERNALTA
5).

Poucos estudos têm apontado o trabalho como fator de risco para adoecimento mental. Dentre eles, observase uma atenção especial com relação ao adoecimento de servidores públicos da educação, com destaque para profissionais da área da educação. Dessa forma, o sofrimento psíquico tem sido uma das maiores causas de afastamento das atividades laborais e, por conseguinte, constitui-se em um desafio para os gestores públicos (BATISTA, MOREIRA; CARLOTTO, 2013).

$\mathrm{Na}$ tentativa de uma melhor compreensão sobre a relação entre trabalho e adoecimento mental, faz-se necessário mencionar alguns conceitos ligados a essa díade. Partindo-se do conceito de saúde proposto pela Organização Mundial de Saúde - OMS e de uma proposta epidemiológica abordar-se-á a relação entre saúde e trabalho, bem como a prevalência de psicopatologias relacionadas ao trabalho (BIROLIM et al., 2019).

"Para que não haja a violação a
saúde mental do trabalhador,
cabendo este ficar atento a
construção de um meio ambiente de
trabalho saudável, para que não
ocorra situações que gerem a
responsabilidade civil e os
afastamentos da atividade laboral."
(INTERNALTA 2).

Essa discussão é fundamental para uma reflexão sobre as pesquisas que falam sobre as causas do afastamento de servidores públicos da educação. Considerando os estudos vistos e disponibilizado para pesquisa sobre afastamentos e saúde mental, evidenciouse um grande índice de afastamentos de servidores por ocasião de "transtornos mentais".

\footnotetext{
"Por isso que, o abuso das horas extras, podem desenvolver diversos problemas de saúde corporal e causar prejuízos a produtividade e lucratividade da empresa, e por conta dos resultados o empregado põe risco a sua saúde, e chega ao ápice de exaustão, que promove o afastamento da empresa." (INTERNALTA 8).
} 


\section{Dano a saúde e trabalho}

É evidente que pessoas com distúrbio psicológico, sofrimento psicológico ou doença mental tem a capacidade para o trabalho comprometida (COSTA， BARBOSA; CARRARO, 2014).

“A dimensão desse quadro e a generalização do termo constituem preocupações de entidades como o Conselho Federal de Psicologia, que teme estar ocorrendo uma proliferação indiscriminada de diagnósticos. Essa posição não constitui a negação da doença, e sim a adoção de uma postura crítica perante uma lógica que busca causas orgânicas para problemas de diferentes ordens, um fenômeno social conhecido por medicalização, definido como "o processo por meio do qual as questões da vida social (...) são reduzidas a um tipo de racionalidade que vincula artificialmente a dificuldade de adaptação às normas sociais a determinismos orgânicos que se expressariam no adoecimento do indivíduo." (INTERNALTA 1).

Nesta oportunidade, podem ser citados alguns exemplos de consequências do adoecimento mental relacionado ao trabalho, tais como: redução da produtividade com o aumento da taxa de erros em procedimentos e a quebra do ritmo de produção - e, consequentemente, da rentabilidade; conflitos interpessoais, entre pessoas no seu local de trabalho, originando um número incalculável de ações trabalhistas e também de naturezas outras - como as ligadas aos direitos do consumidor; acidentes de trabalho, com envolvimento do profissional, muitas vezes com reflexos de longo prazo; aumento do custo de vida por diversos motivos, como aquisição de medicamentos e consultas médicas - com sensibilização para outros tipos de transtornos, etc. (ESTEVES-FERREIRA; SANTOS; RIGOLON, 2014).

Percebe-se, ainda, que o surgimento de transtornos mentais oriundos do ambiente de trabalho pode ser capaz de afetar o relacionamento interpessoal dos trabalhadores, conduzindo-os aos mais diversos tipos de conflitos, tais como: transtornos relacionados ao estresse; transtorno de estresse pós-traumático; transtornos depressivos; transtornos não orgânicos de sono; transtornos mentais e de comportamento decorrentes do uso de álcool; transtorno obsessivo-compulsivo e alterações e transtornos de personalidade. (SILVA; CARVALHO, 2016).
"Definir transtorno mental é difícil porque não se trata de uma condição unitária, mas de um grupo de transtornos com alguns pontos em comum. Há um intenso debate acerca de quais condições são ou devem ser incluídas na definição de transtornos mentais." (INTERNALTA 4).

O estudo sobre os desdobramentos psíquicos da fadiga, da servidão e da humilhação são precursores notáveis das atuais constatações sobre esgotamento profissional - burnout, depressões e suicídios decorrentes de pressões 
organizacionais e de assédio moral. De acordo ainda com os autores em comento, têm sido constantes e variadas, no Brasil, as situações de exploração da saúde mental dos trabalhadores e dos sentimentos e estimas que habitam suas mentes. (SILVA; CARVALHO, 2016).

“Amar é uma faculdade, cuidar é um dever, não existe a possibilidade de obrigar um indivíduo que apresenta distúrbios de personalidade de ter a faculdade do afeto, do sentimento. A pessoa portadora de transtornos de personalidade, no que se refere às relações de afetividade, possui dificuldade de se relacionar, ela é incapaz de estabelecer ligações duradouras e profundas." (INTERNALTA 9).

O acosso psíquico no trabalho atinge, em um primeiro momento, a mente do empregado, causando-lhe danos de ordem moral e psíquica de variada intensidade e sob diversas modalidades; já em um segundo momento, as agressões morais se refletem no corpo do trabalhador, causando-lhe danos físicos. Além disso, podem provocar-lhe também danos materiais ou patrimoniais, seja sob a forma de prejuízos financeiros, seja por outras lesões como o lucro cessante e a perda de oportunidades (SILVEIRA; ENUMO; BATISTA, 2014).

"Todas as doenças estressantes decorrentes do trabalho - estarem em evidência, é que fomentam discussões na sociedade sobre como coibir práticas que geram o gatilho para estas doenças, bem como criar uma rede de ajuda aos adoecidos." (INTERNALTA 9).
E, finalmente, essas lesões ainda podem refletir nos relacionamentos sociais do trabalhador, afetando diretamente sua convivência familiar e, não raras vezes, produzindo danos reflexos nos membros da família, seja em razão das alterações de seu comportamento, seja em função dos danos físicos sofridos - em face da situação de desemprego - ou mesmo pelo efeito extremo do suicídio.
"As principais causas que levam a prática do assédio moral, assim como apontar as sequelas que permanecem nas vítimas no âmbito profissional, pessoal, inclusive comprometendo a saúde física e mental. Outro aspecto que deve receber uma atenção maior é a recuperação da vítima do trauma sofrido, uma vez que ela não recebe o devido tratamento.' (INTERNALTA 9).

Dessa maneira, a afronta aos direitos da personalidade nem sempre terá conteúdo exclusivamente moral, ou extrapatrimonial, podendo ou não o dano moral, propriamente dito, cumular com o dano material (SILVA; CARVALHO, 2016) também destaca os distúrbios mentais vinculados aos efeitos de vários produtos químicos. Para os autores, agentes biológicos e físicos poderão afetar o sistema nervoso do empregado.

\footnotetext{
"As psicoterapias são direcionadas para pessoas que estejam em intenso desconforto emocional, impedindoas de manter uma boa qualidade de vida. Contudo, diante de indivíduos que não apresentam
} 
constrangimentos morais ou sofrimentos emocionais não seria possível tratar de um sofrimento inexistente." (INTERNALTA 7).

Considerando o desafio de avaliar os efeitos do trabalho na saúde desses trabalhadores e das diversas propostas teóricas e metodológicas elaboradas na perspectiva de apresentar modelos para estudar a dimensão do adoecimento relacionado ao trabalho, o presente estudo utiliza o modelo demanda-controle, que tem foco no modo de organização do trabalho e busca identificar a forma como o trabalhador vivencia seu contexto de trabalho. O objetivo deste estudo é determinar a associação entre o distúrbio de voz e o estresse no trabalho docente entre professoras (DIEHL; MARIN, 2016).

"Toda e qualquer conduta abusiva manifestando-se sobretudo por comportamentos, palavras, atos, gestos, escritos que possam trazer dano à personalidade, à dignidade ou à integridade física ou psíquica de uma pessoa, pôr em perigo seu emprego ou degradar o ambiente de trabalho." (INTERNALTA 12).

\section{Políticas públicas voltada para saúde e trabalho}

Desde anos atrás, tem iniciado uma maior atenção para a saúde dos trabalhadores do mercado formal $\mathrm{e}$ informal em todo o mundo. No Brasil, é que veio à tona como um desafio a ser enfrentado em termos psicossociais e legal, onde as empresas tiveram que mudar as práticas de gerir seus colaboradores para atender as necessidades físicas emocionais dos mesmos (SOUZA et al., 2017).

\footnotetext{
"Se do trabalhador operário é obtida uma maior produtividade, isso se traduzirá em maiores ganhos de capital. Mas os limites éticos de exploração e as condições de trabalho desse trabalhador operário nem sempre são observados." (INTERNALTA 3).
}

Mais recentemente, os desafios enfrentados pelos indivíduos por causa do excesso de trabalho, alto índice de estresse, constantes acidentes de trabalho, fez o governo repensar as formas de melhoria na saúde pública devido aos altos gastos ocasionados aos cofres públicos para conseguir atender a essas pessoas, passando assim a ser de interesse do mesmo investir em ações preventivas e assistencialistas (SILVA, 2015).

\begin{abstract}
"A violência moral no trabalho não é nenhuma novidade. Ela existe há muito em todo o mundo. O que é novo são a gravidade, a generalização e a banalização do problema. O terror psicológico atinge o âmbito do trabalho e fere a estrutura emocional-sentimental do indivíduo." (INTERNALTA 10).
\end{abstract}

Diante de meditações, procura-se entender as grandes mudanças do mercado de trabalho nos últimos anos e trazer soluções para melhoria e prevenção de doenças ocasionadas pelo trabalho, como também acidentes de trabalho, trazendo reuniões, congressos, conferências, com finalidade de discutir novas formas de 
treinar, capacitar e desenvolver o pessoal

na conscientização do uso de

Equipamentos de Proteção Individual (ARAÚJO, PALMA; ARAÚJO, 2017).

"O respeito que se deve aos funcionários não implica que não sejam investigados. Não constituem tampouco o delito simples indelicadezas ou petulâncias, infrações a regra do cerimonial ou recusas, como a não aceitação de um convite ou restituição de uma condecoração formalmente não injuriosas". Importante observar que o crime configura-se ainda que o funcionário público não esteja no regular exercício da função, mas é ofendido em razão dela (nexo funcional)". (INTERNALTA 13).

A Organização Internacional do Trabalho (OIT) afirma ocorrer todos os anos cerca de 270 milhões de acidentes do trabalho em todo o mundo, sucedendo que desse número, cerca de 2 milhões são fatais (CARDOSO, 2014).

As iniciativas no Brasil em forma de ações dentro da sociedade vêm se consolidando como políticas públicas de atenção integral em Saúde do Trabalhador (ST) como as ações assistenciais, promocionais e de vigilância e prevenção das doenças agravantes ligadas ao trabalho. No entanto, ainda existe grandes barreiras à consolidação de programas e ações contribuintes efetivamente para poder assumir avanços nos indicadores nacionais, colocando o país em uma situação considerada crítica quando, em termos comparativos, observa-se as nações socialmente mais desenvolvidas (SILVA, 2015).

A atenção à Saúde do Trabalhador é contemplada por meio da atuação da vigilância dos perigos e riscos inerentes ao trabalho, a assistência à saúde e a abordagem e a conduta apropriadas aos determinantes sociais, individuais ou de grupos, que podem impactar de modo negativo na saúde dos trabalhadores. Com os avanços dos programas, foram criadas estrategicamente as normas regulamentadoras com finalidades exclusivas para cuidar da saúde do trabalhador (CARDOSO et al., 2015).

\begin{abstract}
"O trabalhador necessita de cuidados e proteção dos sindicatos e dos empregadores, tendo em vista que possui uma peculiaridade de fragilidade econômica, além de ser o elo que une a força sindical ao empresário." (INTERNALTA 17).
\end{abstract}

A Saúde do Trabalhador tem assumido novos caminhos focando na prevenção e promoção da saúde necessitando de planejamento estratégico para o alcance dos objetivos. Nesta nova perspectiva de produção de indicadores, o Sistema Único de Saúde (SUS) tem o papel de assumir na geração de dados enquanto instância com acesso maior aos riscos concernentes aos trabalhadores no mercado informal (CARDOSO et al., 2015).

"Em uma realidade que pode conter muitas outras restrições, e que o direito constitucionalmente 
garantido que reside no indescritível contentamento seja garantido a todos os profissionais da rede pública ou privada." (INTERNALTA 14).

Neste contexto, o programa de Políticas Públicas tem como papel estratégico a indução do processo de

\section{CONCLUSÃO}

Os profissionais da educação apresentaram níveis elevados de sofrimento mental, muito superior ao esperado em outras categorias profissionais. As doenças preexistentes, o elevado número de alunos por turma, a carga horária de trabalho no ambiente escolar e a continuidade do trabalho em casa constituíram situações que corroboram com o sofrimento mental.

É perceptível a necessidade de ampliar a investigação, no sentido de melhor compreender a gênese do sofrimento mental dos professores, oferecendo subsídios para a produção de mudanças significativas, visando à melhoria de saúde destes, agindo nos processos determinantes do adoecimento e não através da simples medicalização.

A associação entre fatores deve constituir passo inicial e não conclusivo da investigação da determinação da situação. A compreensão profunda da gênese do sofrimento mental dos professores exige o conhecimento dos processos de aplicação dos resultados das pesquisas em soluções no campo das políticas públicas e modelos de atenção à saúde, buscando aperfeiçoar o desempenho do SUS e a melhoria das condições de vida e saúde da população (NEFFA, 2015).

determinação que ocorrem nos níveis singular, particular e geral, assim como das correlações que se estabelecem entre esses níveis, o que foge do alcance deste trabalho. 


\section{REFERÊNCIAS}

ARAÚJO, T. M.; PALMA, T. D. F.; ARAÚJO, N. D. C. Work-related mental health surveillance in Brazil:

Characteristics, difficulties, and challenges. Ciência e Saúde Coletiva, v. 22, n. 10, p. 3235-3246, 2017.

BATISTA, J. B.V.; MOREIRA, A. M.; CARLOTTO, M. S. Depressão como Causa de Afastamento do Trabalho: Um Estudo com Professores do Ensino Fundamental. Psico, v. 44, n. 2, p. 257262, abr./jun. 2013.

BIROLIM, M. M. et al. Job strain among teachers: Associations with occupational factors according to social support. Ciência e Saúde Coletiva, v. 24, n. 4, p. 1255-1264, 2019.

CARDOSO, M. C. A. et al. Saúde do trabalhador no processo de negociação coletiva no Brasil. São Paulo: Departamento Intersindical de Estatística e Estudos Socioeconômicos. v. 76, 2015.

CARDOSO, M. C. A. Indicadores sobre riscos psicossociais no trabalho. In:

SILVEIRA, M. A. (Org.). Aspectos psicossociais e sustentabilidade em organizações: saúde, segurança e qualidade de vida no trabalho. Campinas: Centro de Tecnologia da Informação Renato Archer, 2014. p. 129-144.

CORTEZ, P. A. et al. A saúde docente no trabalho: apontamentos a partir da literatura recente. Cadernos de Saúde Coletiva [on-line], Rio de Janeiro, v. 25, n. 1, p. 113-122, 2017.

COSTA M. S. G. A.; BARBOSA N. D.; CARRARO P. R. A importância do trabalho do psicólogo escolar aos docentes em escolas públicas. Revista Eixo, v. 3, n. 2, julho de 2014.
DIEHL, L.; MARIN, A. H. Adoecimento Mental em Professores Brasileiros: Revisão Sistemática da Literatura. Estudos Interdisciplinares em Psicologia, v. 7, n. 2, dez de 2016.

DIEHL, L.; CARLOTTO, M. S.

Conhecimento de professores sobre a Síndrome de Burnout: processo, fatores de risco e consequências. Psicologia em estudo, v.19, n.4, p.741-752. 2014.

ESTEVES-FERREIRA, A. A.; SANTOS, D. E.; RIGOLON, R. G. Avaliação comparativa dos sintomas da Síndrome de Burnout em professores de escolas públicas e privadas. Revista Brasileira de Educação, v.19, n.59, p.987-1002, 2014.

FAVATTO, N. C.; BOTH, J. Reasons for abandonment and staying in the teaching career in physical education. Revista Brasileira de Ciências do Esporte, v. 41, n. 2, p. 127-134, 2019.

FAVATTO, N. C.; BOTH, J. Motivos para abandono e permanência na carreira docente em educação física. Revista Brasileira de Ciências do Esporte, v. 41, n. 2, abr.jun., p. 127-134, 2018.

MARANGONI, V. S. L. et al. Afastamento laboral por transtornos mentais entre os servidores da prefeitura municipal de Manaus: uma análise preliminar. Semina: Ciências Biológicas e da Saúde, v. 37, n. 2, p. 13, 2016.

MEDEIROS, G. T. DE. et al. Educação permanente em saúde mental: Relato de experiência. Interface: Communication Health Education, v. 20, n. 57, p. 475483, 2016.

NEFFA, C. J. O trabalho humano e sua centralidade. Ciências do Trabalho, São Paulo, n. 4, p. 7-26, 2015.

SILVA, E. P. Adoecimento e sofrimento de professores universitários: dimensões 
afetivas e ético-políticas. Psicologia: teoria e prática. 2015.

SILVA, E. S. Desemprego e desgaste mental: desafio as políticas públicas e aos sindicatos. Ciências do Trabalho, São Paulo, n. 4, p. 89-109, 2015.

SILVA, T. R.; CARVALHO E. A. Depressão em professores universitários: uma revisão da literatura brasileira. 2016.
SOARES, A. G. S. et al. Public school teachers' perceptions about mental health. Revista de Saúde Pública, v. 48, n. 6, p. 940-948, 2014.

SOUZA, K. R. et al. A nova organização do trabalho na universidade pública: Consequências coletivas da precarização na saúde dos docentes. Ciência e Saúde Coletiva, v. 22, n. 11, p. 3667-3676, 2017. 